\title{
JAKOB NIELSEN'S HEURISTICS IN SELECTED ELEMENTS OF INTERFACE DESIGN OF SELECTED BLOGS
}

\section{Magdalena Mirkowicz' Grzegorz Grodner²}

\begin{abstract}
The authors describe issues related to the phenomenon of blogs as a channel of communication in relation to Polish blogosphere. The main hypothesis is assuming the pursuit of the Polish blogosphere for proper technological development. The methodology of the research is based on quantitative analysis of the occurrence of Jakob Nielsen's heuristics, within the studied 50 randomly selected Polish blogs. The methodology is based on an analysis of the case aimed at confirming or denying the occurrence of the heuristics. As a result of the conducted research, the occurrence level of heuristics in the studied group was confirmed.
\end{abstract}

Key words: communication channels, blogosphere, blogs, web usability, Nielsen heuristics, usability, website functionality, communication skills, user experience

\section{INTRODUCTION}

Since blogs became an accepted medium of communication, their creators strive to optimize their appearance and improve their functionality and readability.

There are many definitions of blogs, according to D.M. Scott, an eminent online marketing strategist, "blogs are independent, web-based journals, presenting opinions on every topic, (...) and running a blog provides, both an expert and a layman, an easy way to enter and present their opinions through the market of online ideas." [Scott, 2009, p. 71] Also, in the report "Blog is ... a blog. Blogs through bloggers' eyes", which is a qualitative study carried out by the Institute of Literary Research of the Polish Academy of Sciences and gazeta.pl, it's said that "Blog (weblog - a web journal, diary) is a type of website where the author places dated entries, displayed sequentially, from the latest ones. Usually the note has a title and the date of its publication, also readers have the option of posting their own comments under each entry." [Gumkowska, Maryl, Toczyski, 2009, p. 5]

Blogs are a sender-transmission-recipient communication channel. Arguably, blogs date back to the Hunter S. Thompson and his gonzo journalism in the $60 \mathrm{~s} . .$. But recognized for their use in commercialization of the web and ease of manipulation of the pub-

\footnotetext{
Listener of a PhD seminar on media science, University of Information Technology and Management in Rzeszow, e-mail: m.mirkowicz@dokorat.wsiz.rzeszow.pl $2 \quad$ Listener of a PhD seminar on media science, University of Information Technology and Management in Rzeszow, e-mail: g.grodner@dokorat.wsiz.rzeszow.pl
} 
lic for political purposes, the blogs came to a wide-spread use in the late 90 s. Most often used to develop sales leads and maintain a user base of devout clientele via guerilla marketing tactics masquerading as "awareness campaigns", blogs continue its prominence in the modern Gig Economy. They remain one of favorite media channels chosen by corporate sponsors, second only to social media campaigns. A plethora of studies continue to hide the decline of the written word media in favor of the instant-gratification of audio visual mediums preferred by the current gen of users, be it Snapchat, Discord, or Youtube. According to a study by Natalia Hatalska from 2015, 33\% of Internet users declare that they read blogs. Regular bloggers also declared that they had made changes in their lifestyle, thanks to the content they found on blogs and videoblogs. The author of this report concludes that bloggers and vloggers (Authors of Blog is ... a blog. Blogs through bloggers' eyes report, defines bloggers and vloggers as authors of blogs and videoblogs) are motivated to run their channels is "the desire to make people aware of various issues and their impact on reality." [Hatalska, 2016, p. 9]

Blogs being a source of a certain type of information are often used as tools for advertising and marketing. The growing functionality of such a website, and thus the scope of using it, requires a well-thought-out design, both in terms of information architecture, appearance and operation. Such design interventions called "web usability" are most widely described by Jakob Nielsen. According to his definition of website usability: "(...) how quickly the user learns to use it, how effective it is during such use, how easily it is remembered, how much error free it is and how much users like using it. If users do not want or can not use different properties, that properties might not exist as well." [Kazimirowicz, 2012, p. 2] A firm formulation of the rules that should be followed to create functional and useful websites leaves no illusions about the fact that when designing a blog, which is a channel of communication and information for a wider or narrower audience, the creator of the blog has to consider a number of usability principles and solutions that are necessary to ensure proper communication. This means controlling the current solutions, as well as adapting to evolving both graphical and technological trends.

The development of blogs is closely related to current technology. Thanks to various platforms or software, a professional looking blog can be created by anyone. [Scott, 2009 , p. 69] Heuristic rating of websites (blogs), has not been widely discussed. The appearance and content of blogs should be analyzed in terms of their usefulness and the use of so-called "good practices" that the creators uses in other website types, such as online stores or corporate websites.

The list of heuristics, or good practices, was developed by Jakob Nielsen - one of the pioneers in the field called User Experience. Gerd Gigerenzer uses the term "adaptive toolbox" for the list of heuristics forms. It's about a set of rules that we use to make decisions in limited situations over time with specific resources or information. Thanks to our personal knowledge and ability to learn, we surf quickly and effectively on the Internet. The activities performed by users flow from the user's intuition, by using familiar tools effectively not from constant analysis and thinking about the techniques of performing interactions from the start. We look for proven interaction patterns that allowing us to reach the goal, minimizing the time of achieving it. [UXPin, 2015, p. 13-14]

Using UI [TechTarget, 2018] patterns does not mean repeating what has already been done before. Patterns are the starting point for the created project, not its final form. Knowing the rules of operation of these patterns, the designer can create the user interface appearance according to his own artistic creativity.

The 10 heuristics are: [NN Group, 2018]

1. Visibility of system status.

2. Match between system and the real world.

3. User control and freedom. 
4. Consistency and standards.

5. Error prevention.

6. Recognition rather than recall.

7. Flexibility and efficiency of use.

8. Aesthetic and minimalist design.

9. Help users recognize, diagnose, and recover from errors.

10. Help and documentation.

The article aims to investigate the occurrence of heuristic theory in practice. The research undertaken on a group of 50 blogs from the Polish blogosphere will consist compliance of their construction and operation with a set of guidelines and assumptions defining the proper usability of websites, as defined by J. Nielsen.

The main hypothesis was formulated, assuming that Polish blogs are striving for proper technological development in terms of usability and aesthetics of interfaces through the use of Jakob Nielsen's heuristics.

The article also formulates auxiliary hypotheses:

- At least one heuristic is used in web blog interfaces

- Among Polish blogs there is not one that would meet all the heuristics

The quantitative research was exploratory and formed the basis for in-depth analysis of the use of J. Nielsen's heuristics on Polish blogs. It concerned the particular use of technological, usability and aesthetic solutions. For the first time, the Authors take up the subject of the J. Nielsen heuristics in relation to the Polish blogosphere. The conducted research and analysis of individual heuristics have been supplemented with examples confirming the occurrence of the discussed heuristics. The research was of one-off character, and the results obtained as a result refer to the blogs of limited scope. The presented results are informative and its aim is to indicate the direction in the discussed area.

\section{METHODOLOGY}

The subject of research on the Polish blogosphere has so far been considered in terms of communication in hypermedia space by prof. B. Gregor and dr hab. D. Kaczorowska-Spychalska in the publication "Blogs in the process of marketing communication". The authors of the publication focused on studying the blogosphere communication process and on readers emotional aspects. A similar approach was taken by dr D. Kozłowska in the article "Mighty blogosphere" in 2016. Apart from the previous themes on the subject of marketing results gained from blogs, the authors of this article decided to analyze the concept of the problem focusing on the construction of information architecture and its impact on the usability of websites such as blogs.

The hypotheses presented above were examined on a group of 50 randomly selected blogs. The choice was made on the basis of Google's search engine results for "blog". The assumption was that the site had the term "blog" in the name or description of the result. The examined group contains blogs from various thematic groups and with diverse popularity and the number of readers. Selected blogs adhere to the assumption that at least three articles have been published on them in the last six months.

The study nature is qualitative and aims to submit or denied any of the 10 Jakob Nielsen's heuristics within the examined site. Each blog has been tested for individual heuristics. The use of each of them on a given blog was discussed by the authors of the study, on the basis of a joint analysis, its reasonableness or lack of reasonableness was determined.

Analyzing the researched blogs, it was determined whether a given blog uses a given heuristic, by the word "occurs" and in the case of non-use - "does not occur". The results were collected in the table and a matrix, then the graphs with the results were 
created.

The analysis presented below shows examples of using each of the selected 11 blogs that met the given heuristics. An e-mail was sent to each of the website owners asking for the option of including a screenshot in this article, consent was received.

The methodology was based on the analysis of a randomly selected group of 50 blogs, which may indicate the occurrence of a potential deviation from the study taking into account the actual number of blogs in the Polish blogosphere.

\section{ANALYSIS OF NIELSEN'S 10 HEURISTICS}

Below is a theoretical description of each of Jakob Nielsen's heuristics, whose theory was transferred to the blog's construction level. The results of the study of the occurrence of individual heuristics and an example of a blog that uses a given heuristic are presented.

\section{Visibility of system status}

In everyday life, we use signs, symbols or tips that are familiar to us at every step. Starting from regular shopping, where we follow the descriptions of shelves, by the symbols on clothing labels, which inform us how to wash, dry and iron the material, for websites, where clicking on different categories, we move to the next subpages. According to J. Nielsen's first heuristic - the system should inform the user about what is currently happening.[NN Group, 2018]. It is easy to refer to the issue of return paths on the website, also known as "breadcrumbs" which, citing Steve Krug (an information technology architect and UX), "show your current position in the site hierarchy." [Krug, 2014, p. 88] Sometimes they contain "You are here" information. The text shows you the overall position, and the return paths - the way you get to it - the difference is analogous to looking at a road map, and reading a detailed description of how to get there somewhere."

In the case of blogs, this feature appears rarely and is not particularly popular. Chart 1. shows that $24 \%$ of the blogs (surveyed for the purposes of this article) meet this heuristic and show the readers the return path on the website. Among blogs using this practice, you can distinguish Podlinski.net blog. This website uses breadcrumbs, as shown in Fig. 1. where on the subpage of the article the user can see in what part of the site he is located. The user has thus gone through the path from the Home Page, through the next subpages, to a specific article and he sees his status all the time.

Chart. 1. First heuristics in the group of 50 blogs.

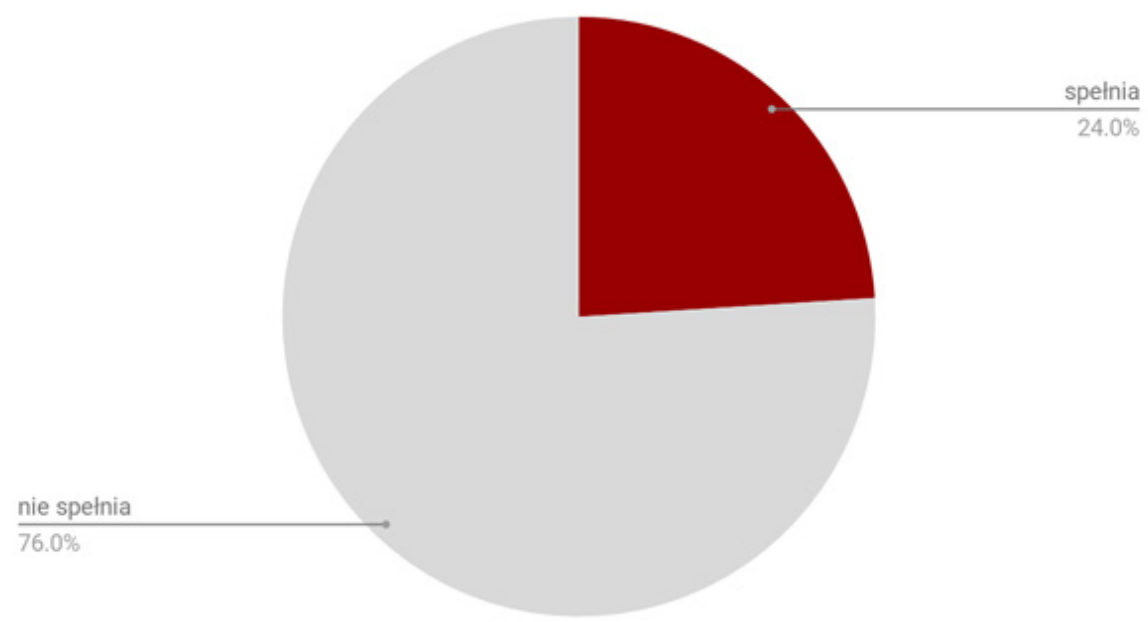

Source: Own elaboration 
Fig. 1. Subpage of the recipe from the blog Podlinski.net showing the status of the system informs the reader in what part of the site he currently is, this is the path Home> Character> Gadgets...

\section{ŁUKASZPODLIŃSSKI}

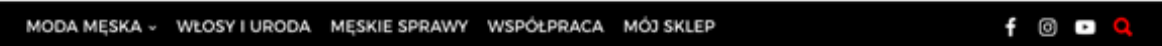
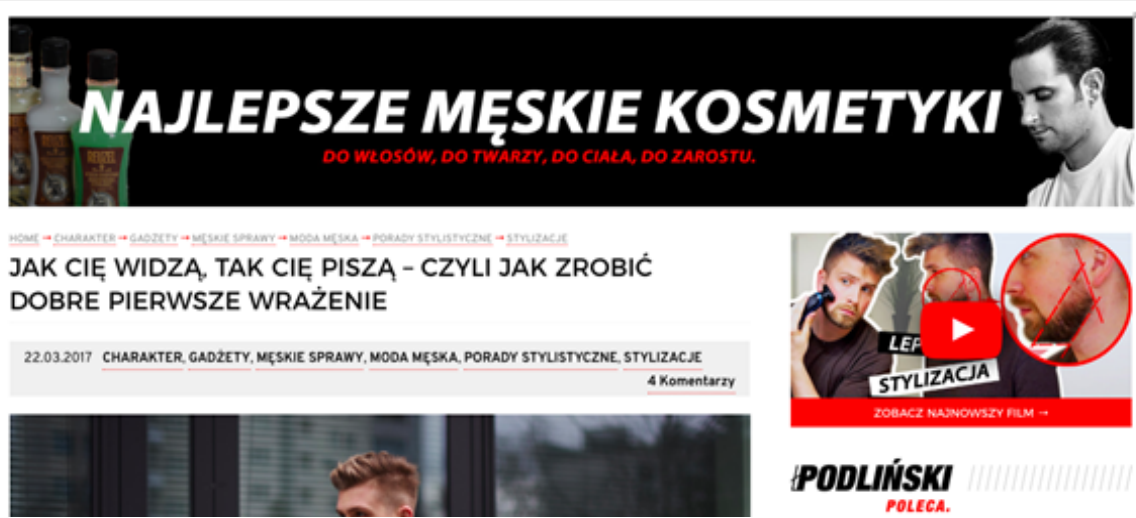

[PODLIŃSKI

Source: https://www.podlinski.net/jak-cie-widza-tak-cie-pisza-czyli-jak-zrobic-dobre-pierwsze-wrazenie/ (Access: 02.08.2018)

Showing the status of the system is also informing the user which menu tab is currently active. After entering the subpage selected from the menu, the navigation element or tab should visually stand out. The distinction may be a change in the font color, change in the color or shape of the element background, underline etc., depending on the designer's creativity. It gives the recipient information that the page on which he is located is active, i.e. highlighted in the menu. In the case of blogs on the group of 50 pages examined, only $30 \%$ use this functionality (Chart 2 ).

Chart 2. First heuristics in the group of 50 blogs.

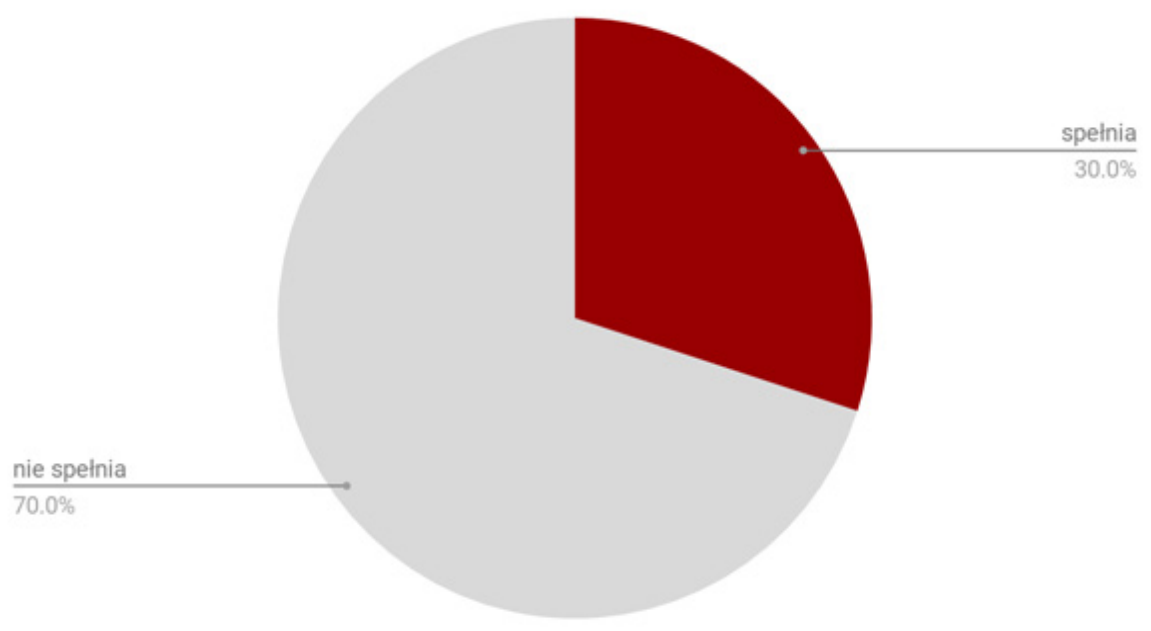

Source: Own elaboration

\section{Match between system and the real world}

The system should use phrases familiar to the user. It should also use terms adopted in everyday life and be understandable to majority of users and tailored to the formal requirements. This is probably the most enigmatic rule, which means that websites 
should be legible, both in the construction of the interface and content. Quoting Krug, "if you decide to browse the content of the site, you are guided by a hierarchy and use helpful signs and symbols." [Krug, 2014, p. 67] Therefore, the use of icons and characters, color associations, or highlighting headers in the interface is extremely important and causes the recipient to be able to navigate the website more easily. The same as for example the messy room is much harder to move around it than an cleaned one.

The compatibility between the system and the reality can also be assigned to Google search results - the page should contain in it a short description that reflects what is on it.

While nalyzing blogs in this study, it was found that as many as $90 \%$ of blog interfaces used signs and symbols in their interface (Figure 3).

Chart. 3. Second heuristics in the group of 50 blogs.

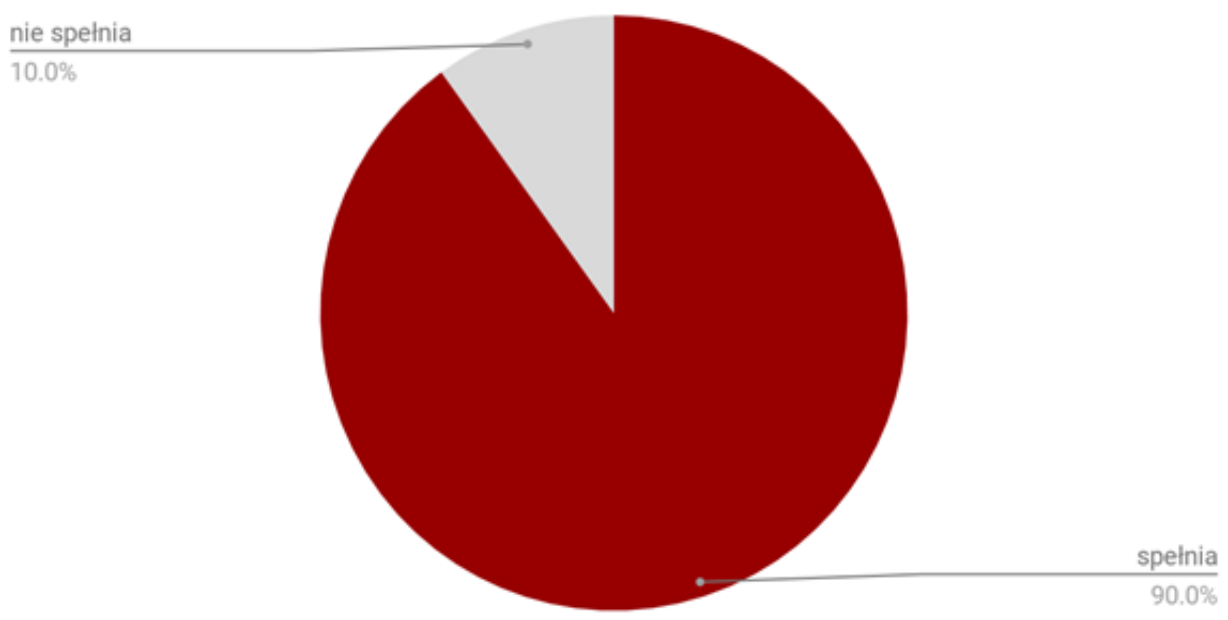

Source: Own elaboration 
An example of the second Nielsen heuristics use is the blog prakreacja.pl (its subjects are the legal aspects of activities in the creative industry). The author uses an accessible legal language on the website, and the interface reflects the subject matter (see Fig. 2). It is worth paying special attention to the logotype, which is a combination of a light bulb (symbol of creativity) and a paragraph (a symbol used in law). The green color used in the interface is also symbolic and refers to the color of the lawyer's toga. The appearance of the blog interface reflects the professional nature of the site.

Fig. 2. Blog devoted to the legal aspects of creative activities, maintaining compatibility between the system and the reality, the appearance of the website, logotype, typography, and coloring are relevant to its content.

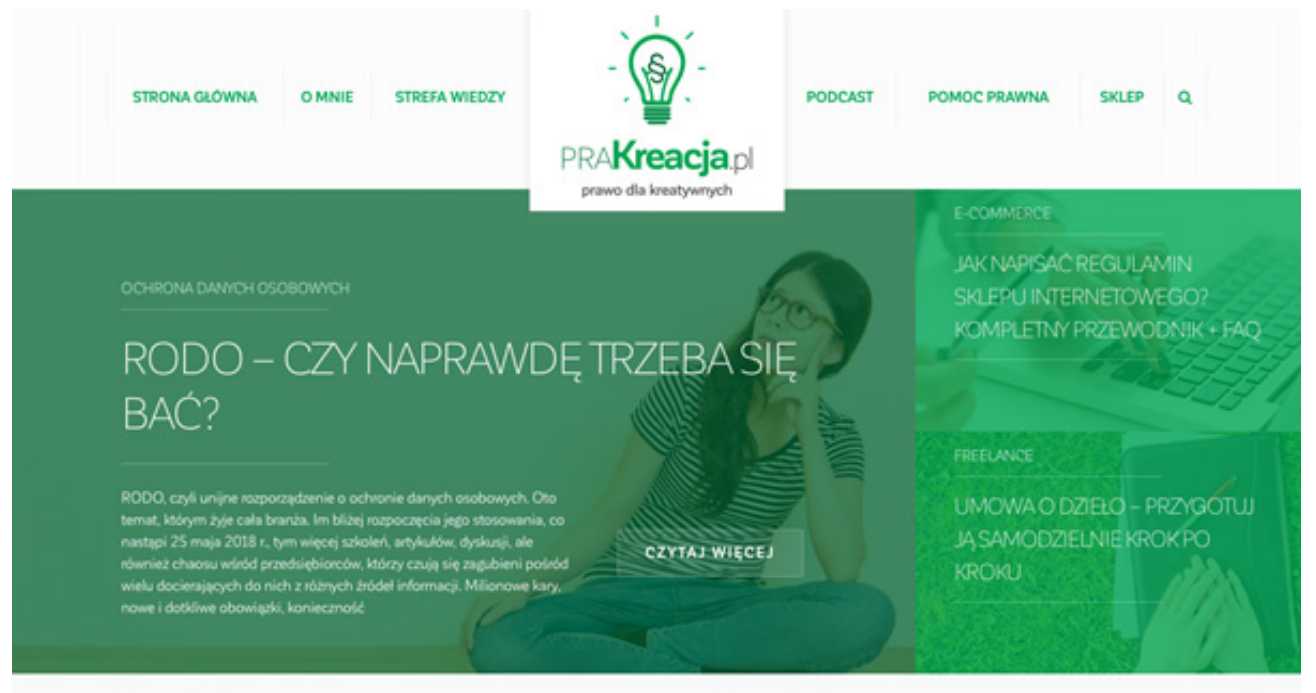

Source: https://prakreacja.pl (Access: 16.07.2018)

\section{User control and freedom}

This stands for undoing and redoing. [NN Group, 2018] Users sometimes use certain functions by mistake, so page creators should remember to give them the ability to feel control over what they do. If they make a mistake, they can undo it, e.g. by editing or deleting their activity. Blogs make it possible through comment systems. Adding comments to entries by readers is a characteristic feature of blogs. Bloggers use a few options to comment on blogs. It can be a built-in plug-in or external systems implemented to the site (e.g. Facebook comment system or Disqus system).

The user who can add a comment should also be able to edit or delete it. In this case, it is about affordances, i.e. the action that users can perform on a given element of the site. Thanks to visual cues, the user gets what he can do by clicking for example a pencil mark, he hints what action the item will perform, in this case it is usually an edition, but he can also add a comment using, for example, a plus or delete it by selecting the trash icon. [UXPin, 2015, p. 32] 
Chart. 4. Third heuristics in the group of 50 blogs.

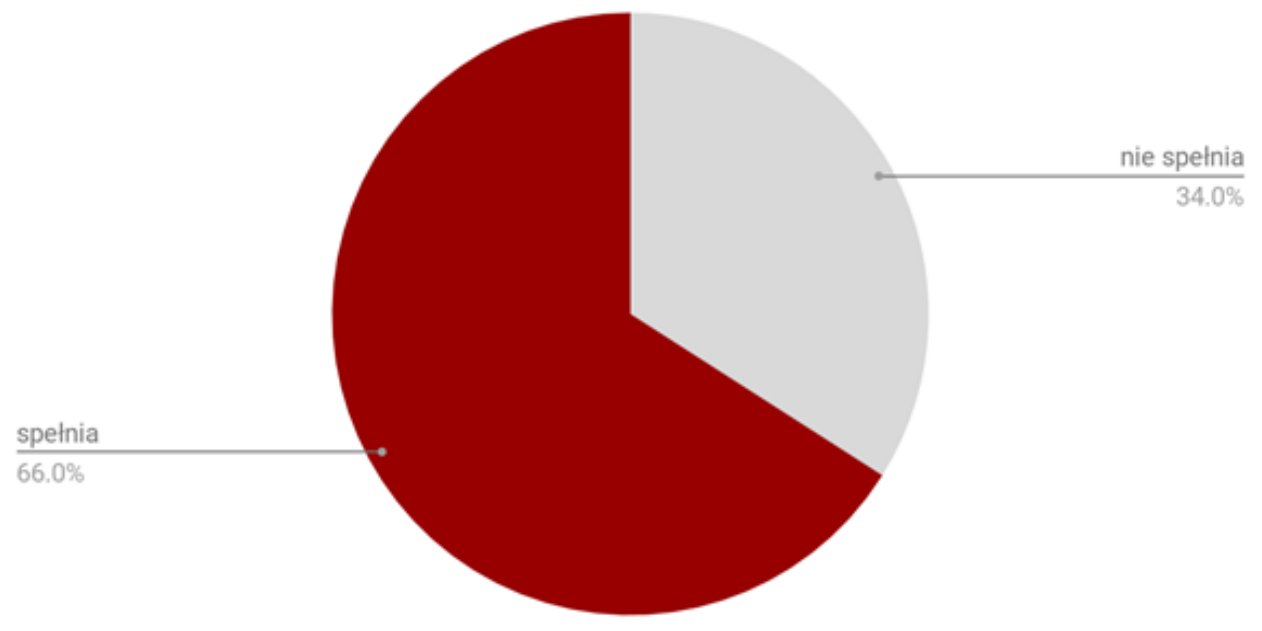

Source: Own elaboration

Analyzing this heuristic on 50 surveyed blogs - 34\% did not have the possibility to edit or delete comments (Chart 4). As an example of a blog using this heuristic is "One Little Smile" blog, which is using the "Disqus" comments system (Figure 4).

Fig. 4. Post subpage focused on the comments, the page gives the user control over the content thanks to the ability to add, edit and delete comments.

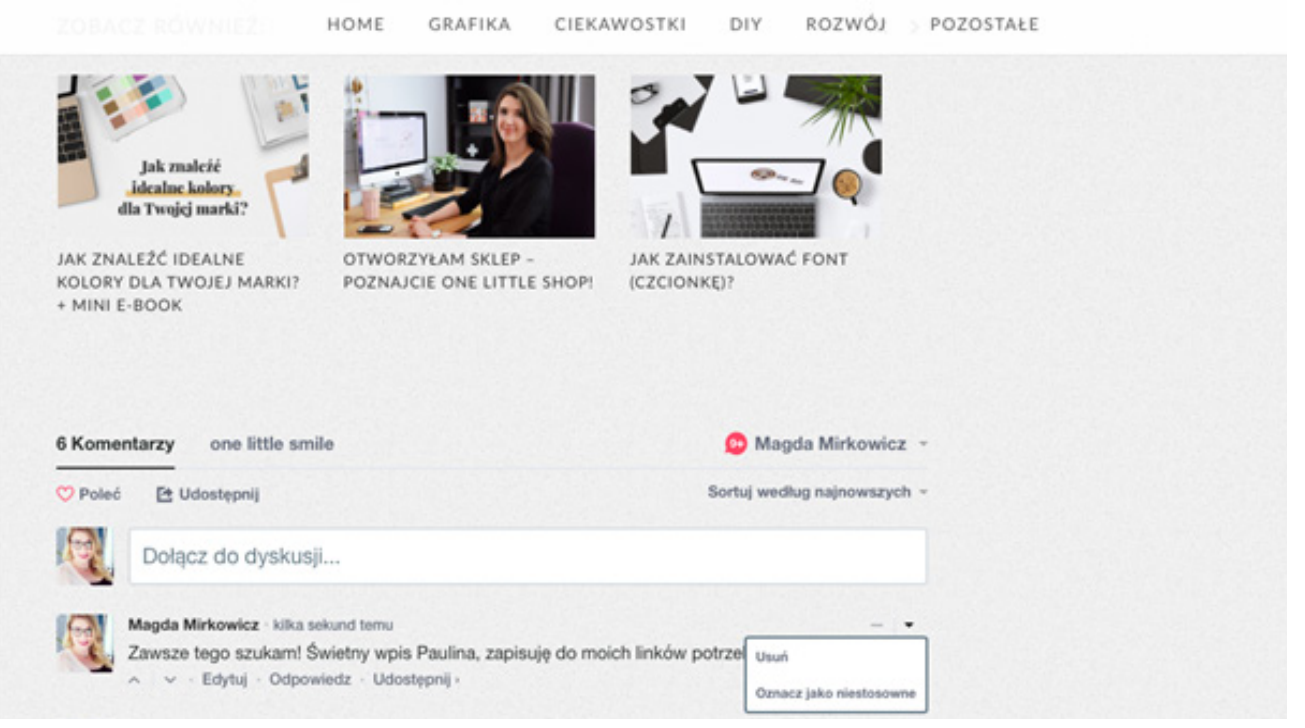

Source: https://onelittlesmile.pl/2018/07/wymiary-grafik-na-facebooku-lipiec-2018.html (Access: 19.07 .2018$)$ 


\section{Consistency and standards}

Using the Internet is dictated by the desire to save time. Users know that they do not have to read every content on the website. Steve Krug sums up this opinion - "we do not read websites, we review them." [Krug, 2014, p. 20-21] The readers are interested in content while visiting the website, they do not read the content carefully, they only look for selective information, words and key phrases. It is easy to relate this concept to the layout of the website and the appearance of its elements. You should not reinvent internet design anew, as people who are accustomed to standards - they usually expect them and "few people, regardless of the technological level, take the time to become familiar with the user manual." [Krug, 2014, p. 38] For example, we know that the button is linking and moving to another subpage. [Krug, 2014, p. 40-51] Users benefit from prior knowledge of the rules of managing their interactions. If we design with a scheme that will be consistently used throughout the site, the user will move around without any problems. It is necessary to ensure that information of the same type is presented in the same way (e.g. using the same icons, buttons, colors).

Fig. 6. The Segritta.pl blog assigns a color scheme for individual categories of the blog.



Source: http://segritta.pl (Access: 16.07.2018)

In the case of blogs, you can indicate, for example, the color scheme assigned for each category. Heuristics are used, among others blog Segritta.pl, where in Fig. 6 you can see the colors assigned to each category of the blog, and on the subpage with the article (Figure 7), the red color assigned to the "lifestyle" category appears as the highlight of this category in the article itself. 
Fig. 7. The Segritta.pl blog adheres to standards and maintains consistency through the preservation of one color scheme for one blog category, the figure shows an example for the lifestyle category.

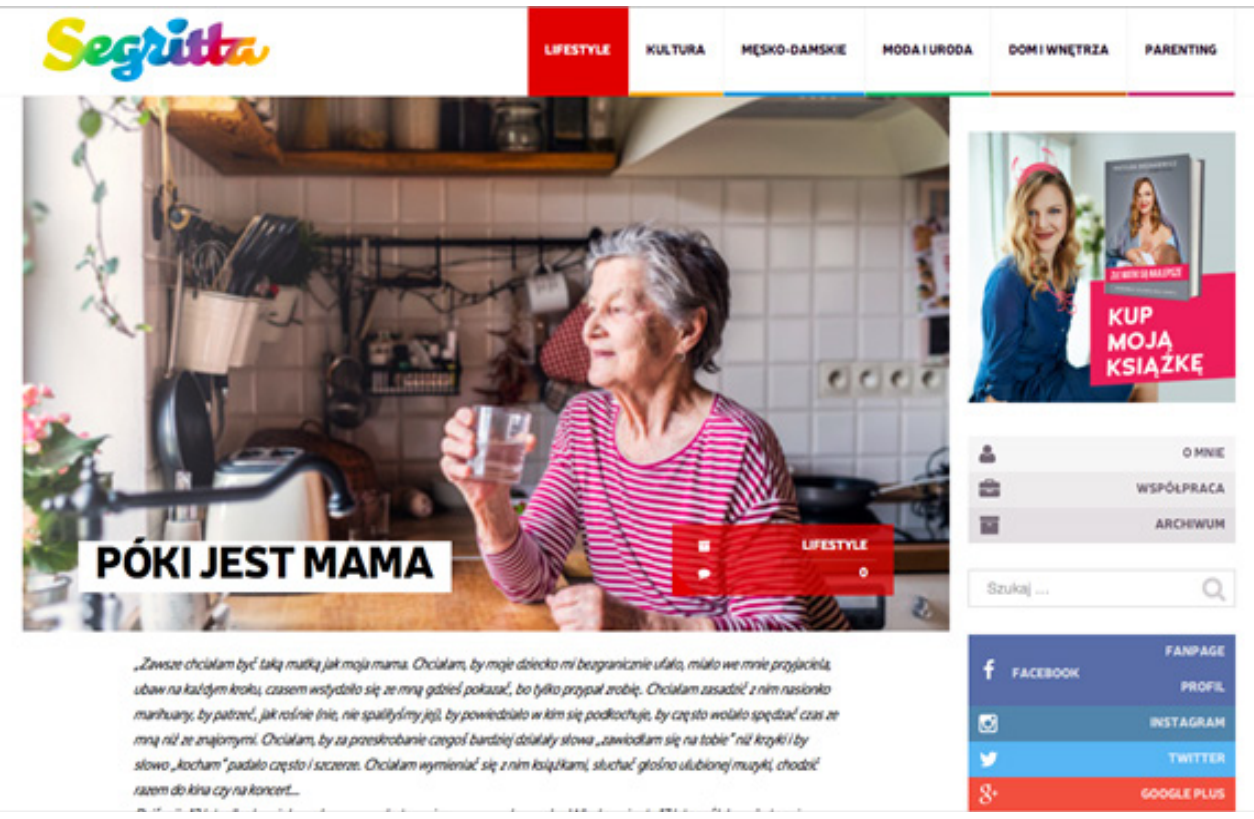

Source: http://segritta.pl/poki-jest-mama/ (Access: 16.07.2018)

Among the 50 bloggers surveyed, the fourth heuristic - Stick to standards and maintain consistency - in this case color and visual, e.g. buttons or typographic elements, meets $70 \%$ of blog interfaces (Chart 5).

Chart. 5. Fourth heuristics in the group of $\mathbf{5 0}$ blogs.

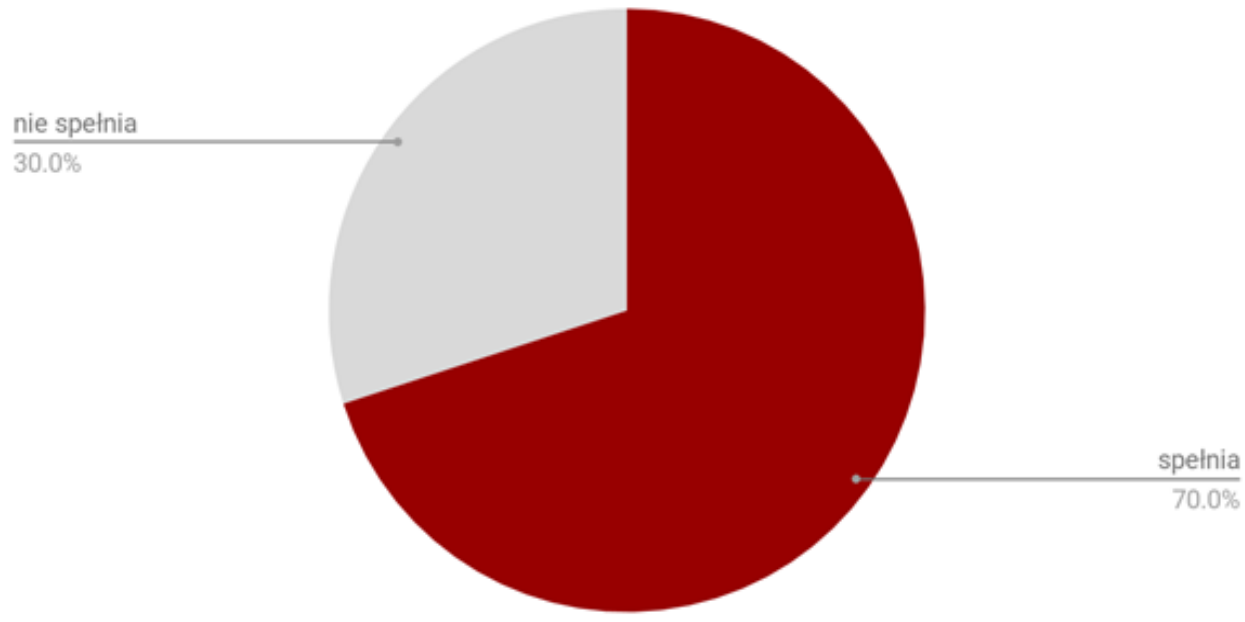

Source: Own elaboration

Design aesthetics is an individual matter, while the operation of the website should be independent of the visitor's graphic preferences. The website should be properly displayed, regardless of the software used by the user, in this case, a web browser. [Laskowski, 2011, p. 2195] Mobile and responsive [Redesign the web, 2012] page versions offer much better user experience, and "users are more successful using websites optimized for mobile phones." [Nielsen, Budiu, 2013, p. 35] Especially in the case of blogs that are often read in a free time, as a form of relaxation or in order to quickly check any information. Therefore, it is worth analyzing this heuristic in terms of proper functioning of blogs 
on different browsers and various browser window widths.

Analyzing the correctness of the operation of Polish blogs, $88 \%$ showed correct operation of the website in terms of responsiveness and operation on mobile devices (Figure 6). As an example of a tested blog, the one which avoided errors in operation is the jacekklosinski.net website, shown in Fig. 8. The blog displays correctly in terms of responsiveness (i.e. regardless of the width of the browser window) and it is fluent on many browsers and shows no errors that would disrupt the user's using this site.

Chart. 6. Fifth heuristics in the group of 50 blogs.

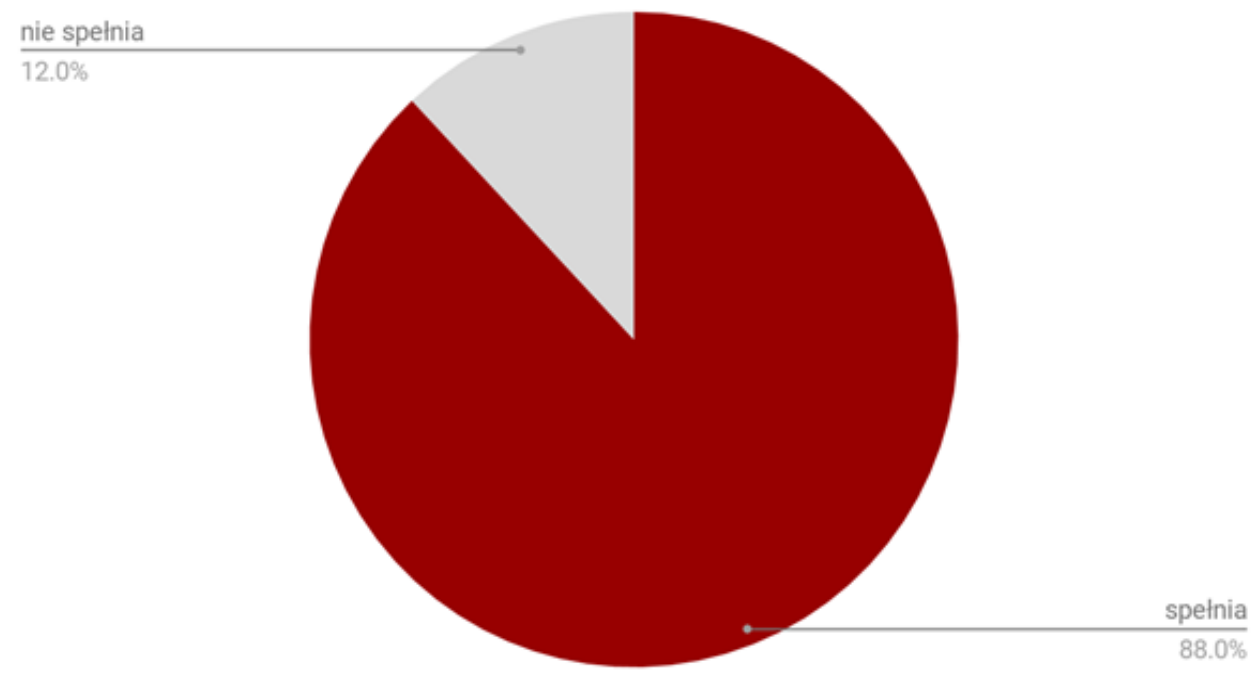

Source: Own elaboration

Fig. 8. Jacek Kłosiński's blog showing the prevention of errors through proper operation in both the desktop version and the responsive version - shown on the smartphone.

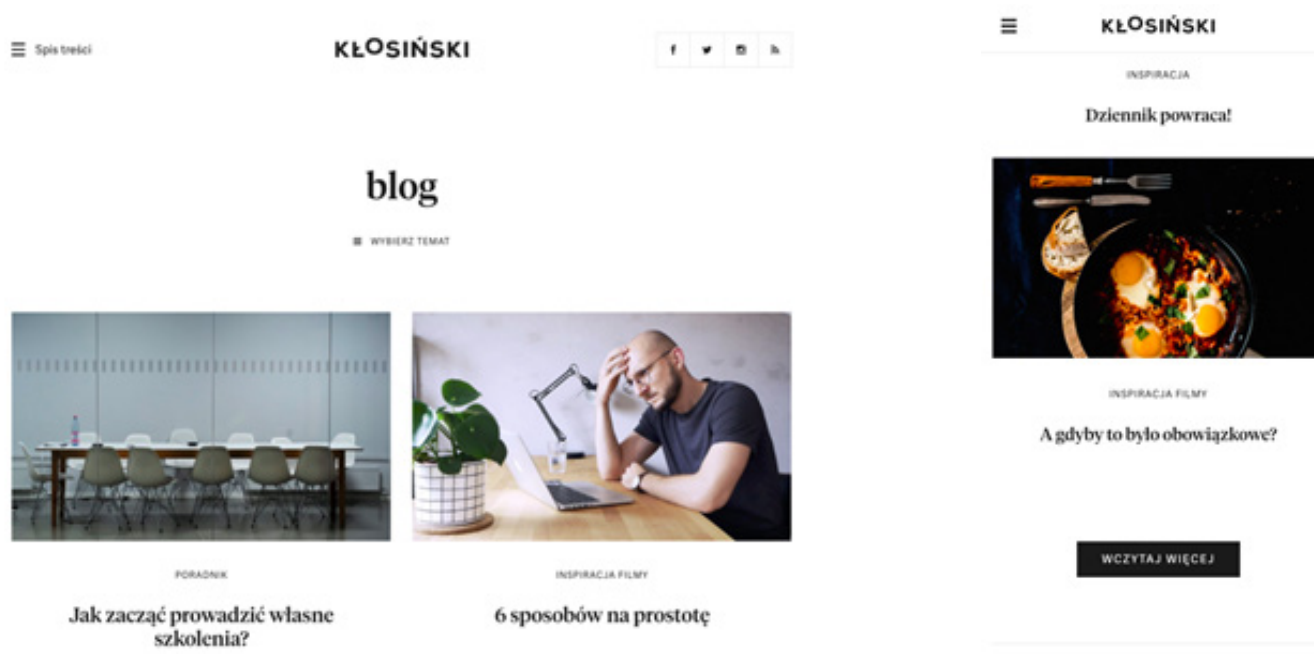

Source: http://klosinski.net/blog/ (Access: 16.07.2018)

\section{Recognition rather than recall}

This principle applies to one of human skills, which often turns out to be unreliable the memory. Forced to memorize various sequences of numbers such as PINs or access codes, various passwords to log in to several systems, we use things that do not involve our memory with a relief. Nielsen proposes a principle that says that the system should 
be designed so that it does not force the user to recall various things. All actions taken by the user should be the result of his conscious choices, and not the saved behaviors. [Laskowski, 2011, p. 4]

Offering blog readers easier access allows them to navigate faster between content, reaching the desired information in a shorter time. If the layout of the page is well-planned and there are similar content in permanent places, then this page does not compel the recipient to think about its contents. There is no need to recall specific titles of entries from the memory, if they are displayed in places where the recipient may associate with them.

An example of using this practice is the worqshop.pl blog. Based on the attached example (see Fig. 9), when we finish reading one of the many entries, we get a list of hints in the form of related topics section. This allows the recipient to reach a wider range of topics in his interests, without having to return to the navigation or previous subpages, on which he will look for a suitable category to satisfy his curiosity on the subject.

Fig. 9. References to related topics under the entry are marked with the heading "See also"
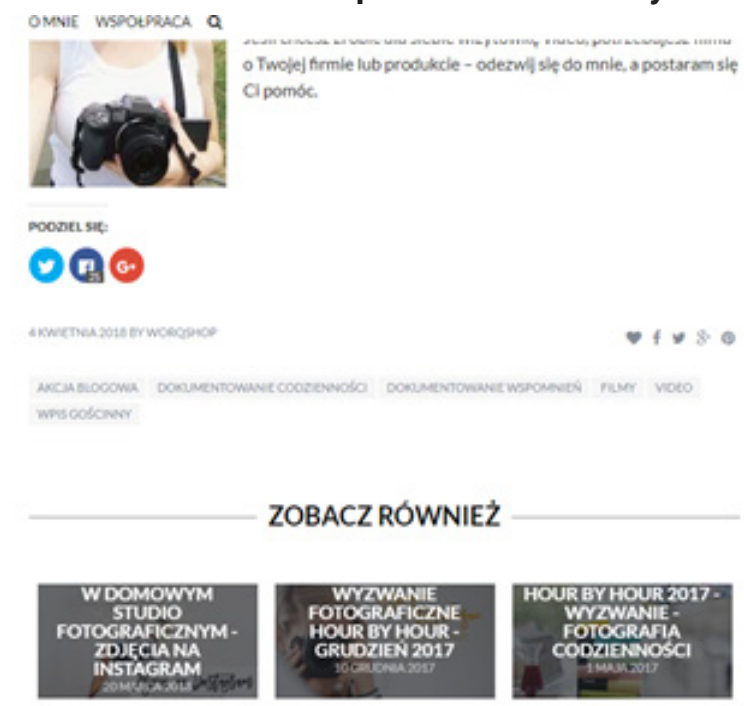

Source: http://worqshop.pl/jak-nagrywac-filmy/ (Access: 18.07.2018) 
Based on the study, it is a common practice to use modules with blogs to refer to similar entries about related topics - the use of this solution was noticed on 35 out of 50 blogs (see Chart 7).

Chart. 7. Sixth heuristics in the group of 50 blogs.

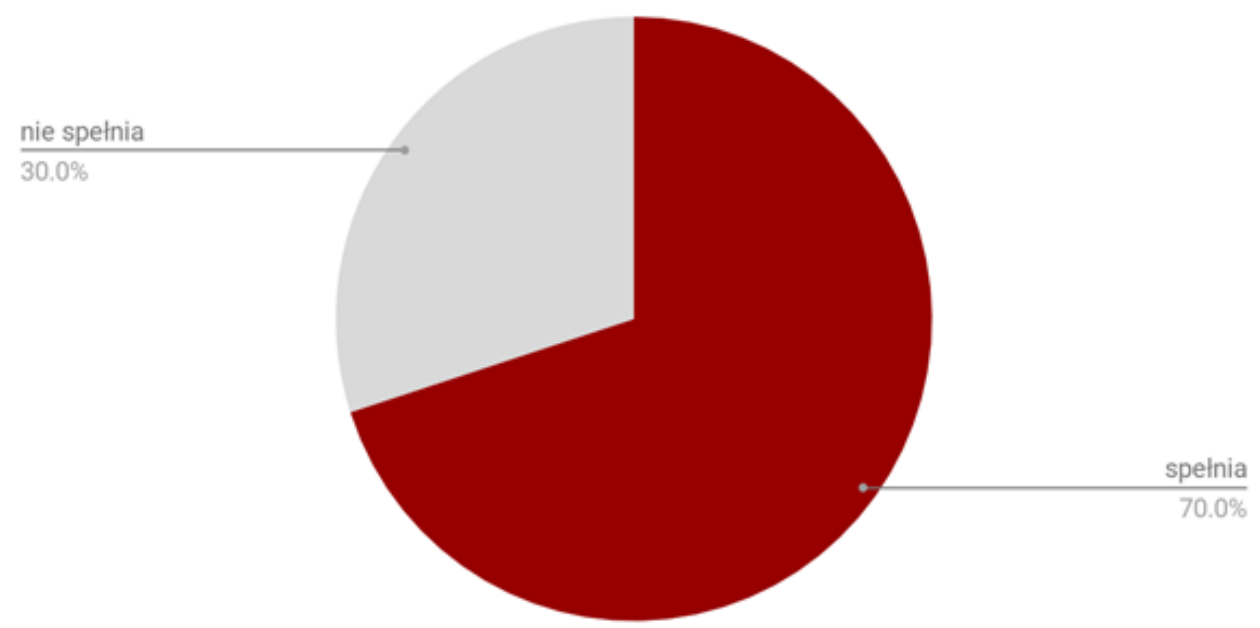

Source: Own elaboration

\section{Flexibility and efficiency of use}

Effective work is the dream of every experienced user. Sometimes, due to the necessity of repeating one activity, we are looking for a subconscious way to accelerate it. The result of a streamlined operation is the time gain.

The principle of ensuring flexibility and efficiency tends mainly to facilitate the work of experienced users, but not necessarily visible to new customers who have been in contact with the product for the first time. Creating a strategic product plan requires knowing the recipients' preferences and having significant data on the subject. The scope of "crawling" after the website can present the effectiveness of the facilities used and the degree of their use by users. [UXPin, 2016, p. 8] Thus, the main goal is to improve work efficiency by facilitating access to frequently used functions. 
Fig. 10. An example of a cumulative list of links to the most important categories of blog content.

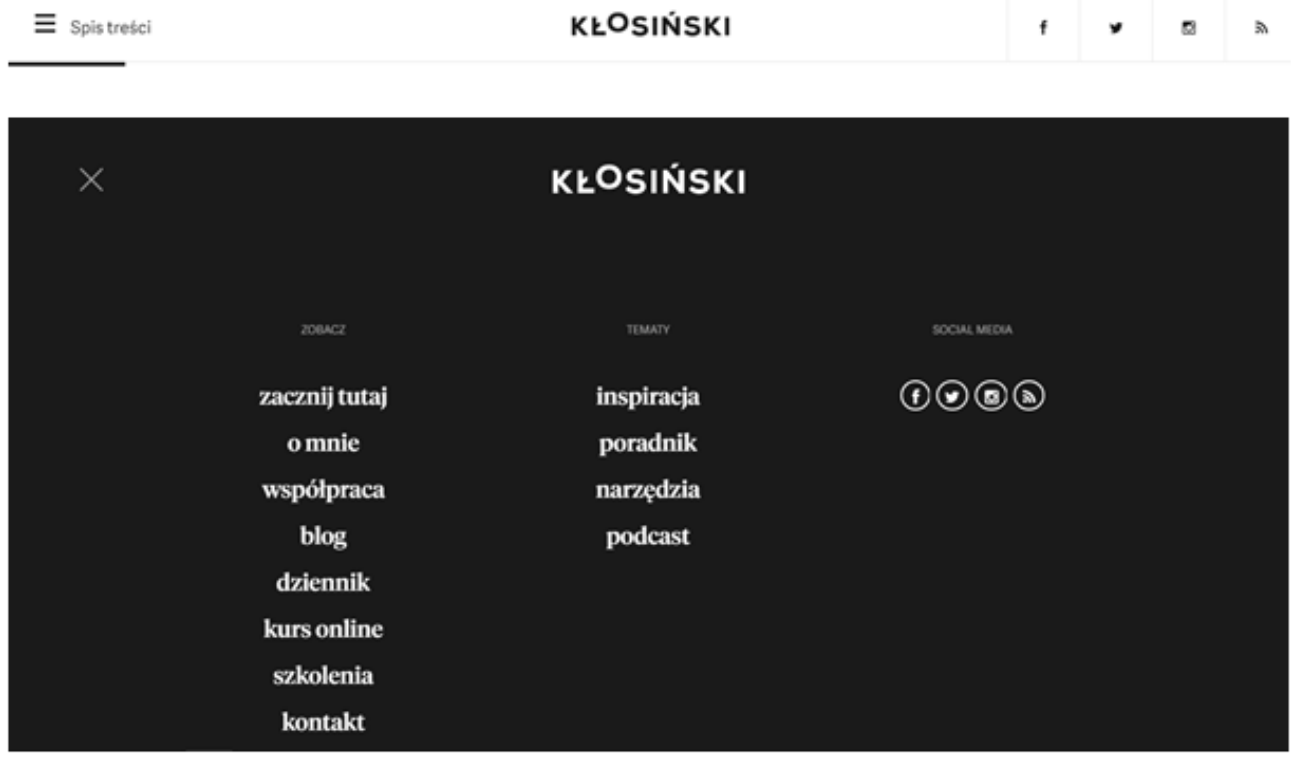

Source: http://klosinski.net/blog/ (Access: 16.07.2018)

By creating a blog, we gain readers interested in the content we provide. Recipients visit the site in search of issues that are assigned to a given category. When designing the graphic interface of the blog, we focus on the visibility and the shortest possible access to the content categories offered. We will facilitate access based on the principle of consistency, i.e. as on the attached example on each subpage, the "shortcuts" transition is placed in the same place as the "Table of contents" button and the icon of a burger commonly associated with the menu (see Figure 10).

Chart. 8. Seventh heuristics in the group of 50 blogs.

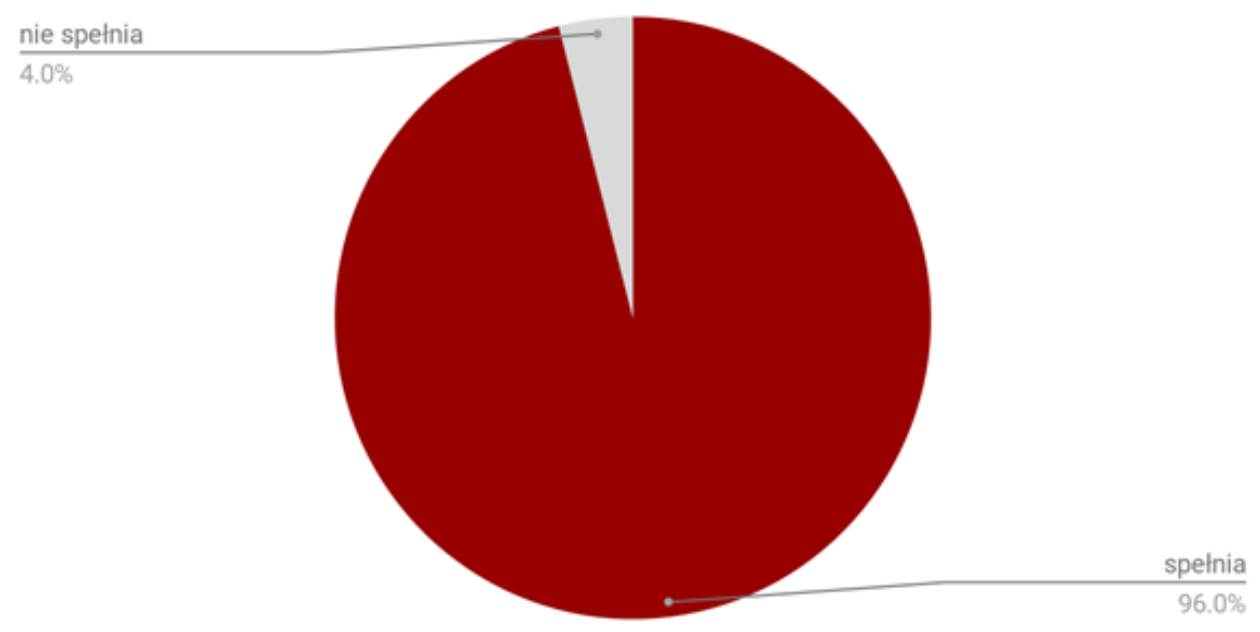

Source: Own elaboration

Within the selected blogs only two did not see the use of this heuristics, while the vast majority, as many as 48 blogs adhere to this principle in their project, offering easy user access to the menu (see chart 8). 


\section{Aesthetic and minimalist design}

Simplicity grabs the attention the attention of the recipient. In last few years trends in internet graphics, used in blogging, are guided by the principle of minimalism. This approach to art opposes past trends of utilizing a wealth of means to express diversified content. The use of uniform forms, limited colors and ordinary geometric shapes creates a neutral background to the presented content. [UXPin, 2017] Recipient, by applying the "less is more" rule, is not distracted by a series of aggressive graphics, and can focus better on content and memorizing information. Solutions that can prevent you from reaching an important message are omitted in this stream. In addition, the unchecked arrangement of elements on the page allows you to quickly orientate yourself on the elements arranged on the screen, increases navigation speed, and as a result, save time. [Laskowski, 2011, p. 5]

Caring for aesthetics and moderation is therefore a very beneficial practical principle and we find it on the most popular websites. Designing a graphic design without unnecessary information or graphics is a challenge and does not define the design as boring and expressionless. Internet blogs dominate the white, neutral background. Coloring is most often very limited, sometimes only to one color accent, which is designed to attract the attention of the recipient to relevant content or buttons. The content layout is limited to the minimum number of columns to avoid creating excessive divisions.

Chart. 9. Eight heuristics in the group of 50 blogs.

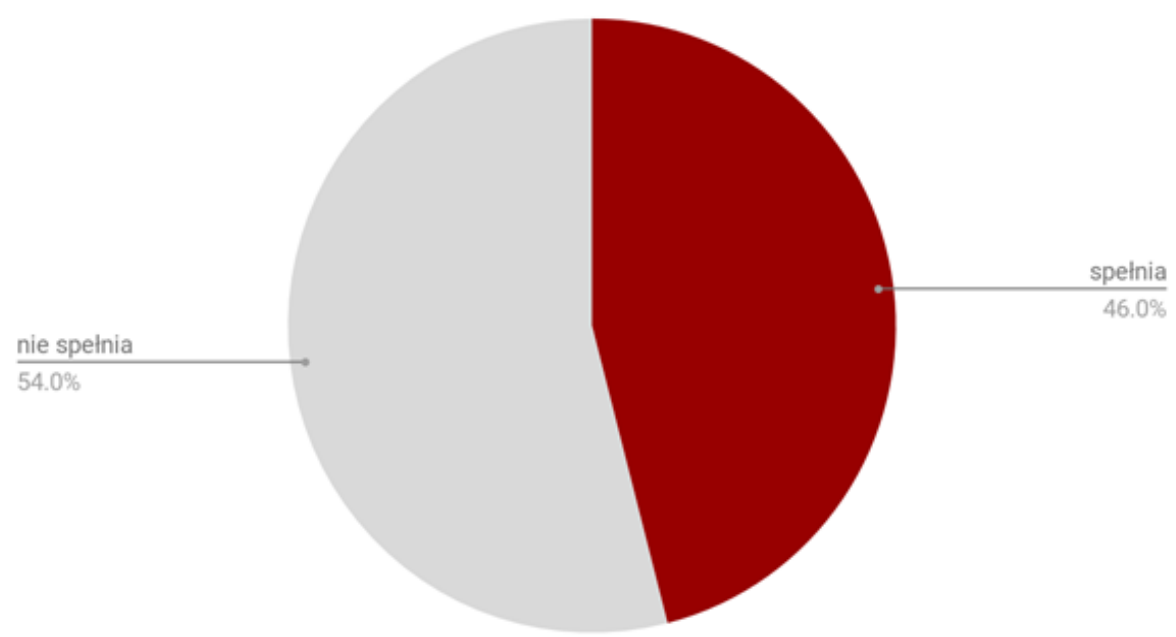

Source: Own elaboration

The minimalist design style among blogs is reflected in 23 out of 50 blogs. However, the majority of surveyed websites are not characterized by a moderate and correctly balanced graphic design layout (see chart 9).

Examples of blogs, whose authors are guided by the principles of minimalism, even not only in terms of internet design, are simplicite.pl and agnieszkakudela.pl (see Figures 11 and 12). 
Fig. 11. A graphic layout of the blog simplicite.pl with dominant white in the background and contrasting typography.
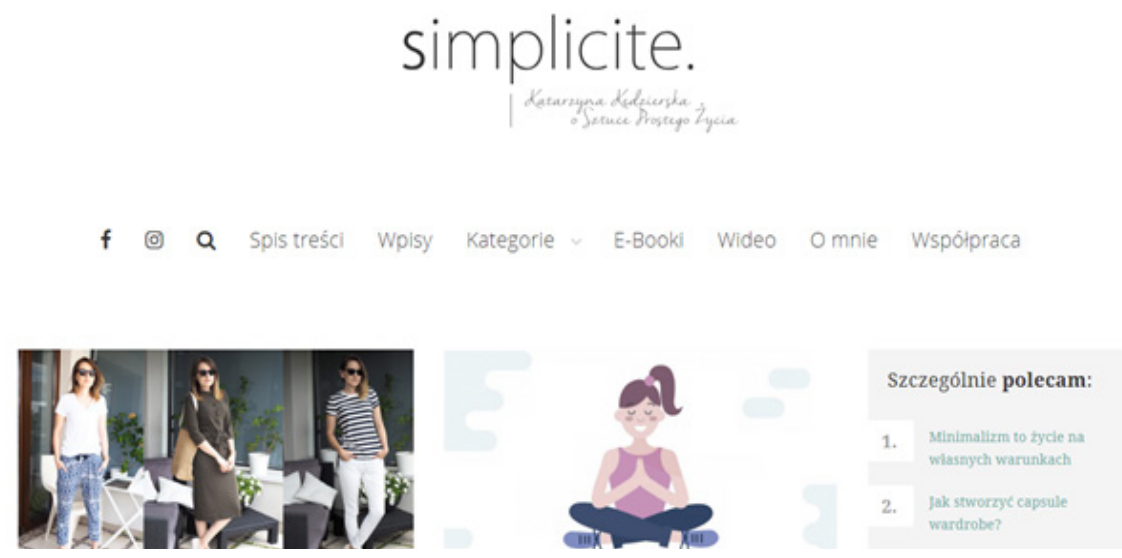

Source: https://simplicite.pl/ (Access: 18-07-2018)

Fig. 12. An example of a graphic layout of a blog with one strong, dominant color accent and a two-column layout.

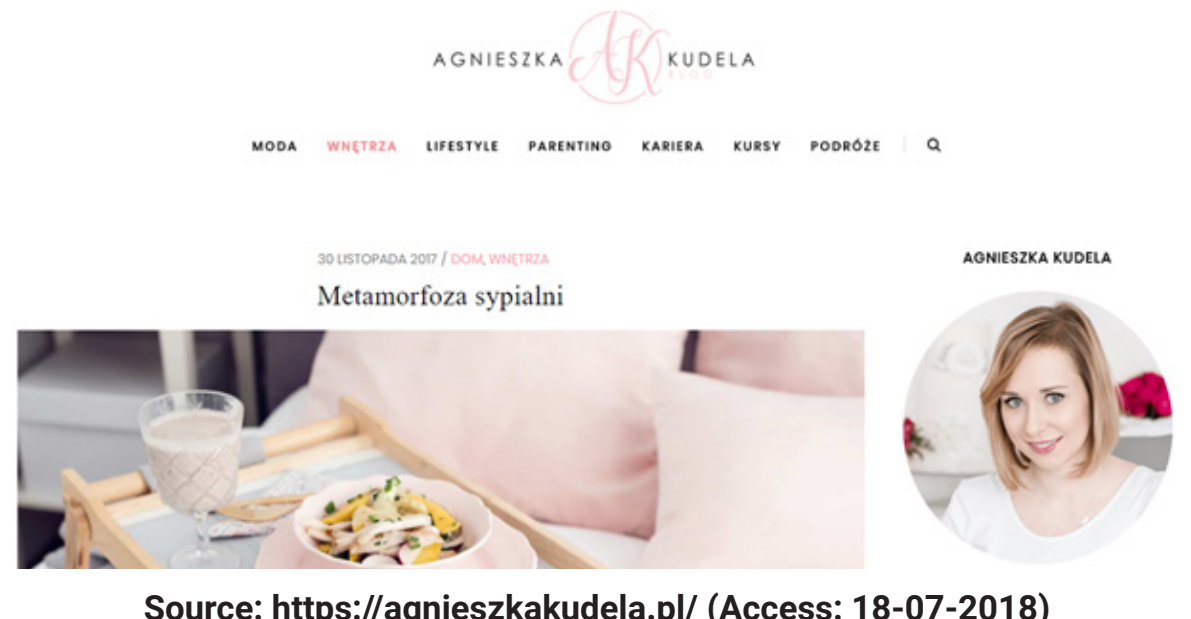

\section{Help users recognize, diagnose, and recover from errors}

As the functionality of the website increases, there are more opportunities to use it and gain information. However, more possibilities are more places where the user can make a mistake. Errors should be expressed in statements understandable to the average user, not just IT specialists. There are types of errors (e.g., 404), which almost everyone knows, but not completely. The fact that we know each one does not mean that everyone will know what is going on and it is worth describing them. It is also good to suggest a solution to the problem. The text information under the warning explains the type of error and allows you to easily return to the main page. [Kazimirowicz, 2012, p. 25]

Analyzing Polish blogs, it can be concluded that in case of error 404 handling - the majority - 40 out of 50 blogs, apply good error handling practice - the ninth heuristic (see Chart 10). 
Chart. 10. Ninth heuristics in the group of 50 blogs.

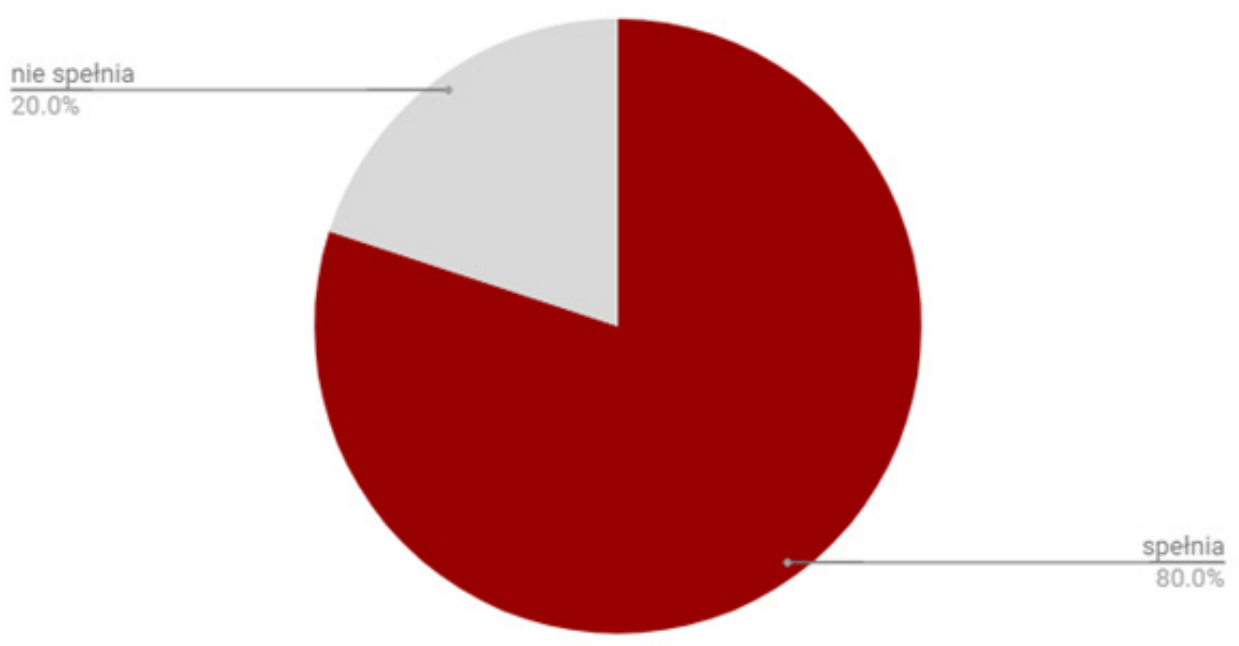

Source: Own elaboration

An example of a blog that uses this practice is, among others Niebezpiecznik.pl (Figure 13). The presented error page is additionally varied with humorous graphics that can make waking rather than annoying - it will make you laugh.

Fig. 13. An example of a graphical resolution of the error information.

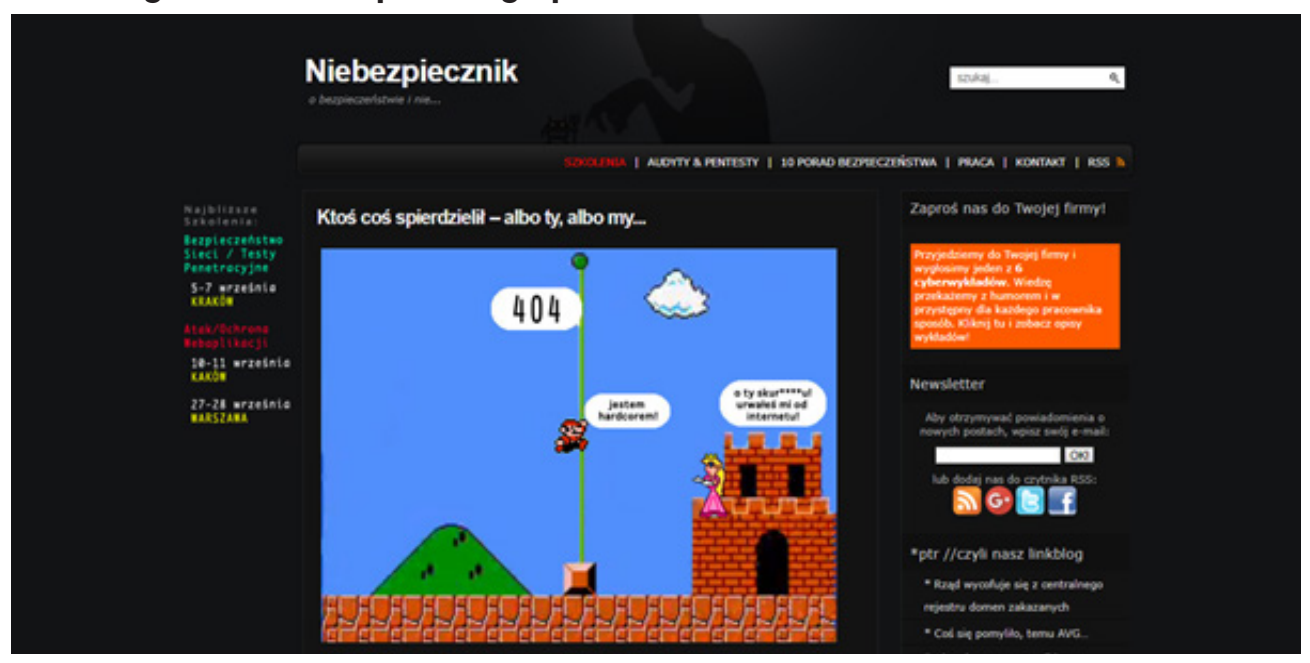

Source: https://niebezpiecznik.pl/colko (Access: 25.07.2018)

Getting into a non-existent page and receiving an error message does not have to be a final stop and a need to return. Such a website may offer a start to further search if it has a search engine (see example in Figure 14). 
Fig. 14. An example of 404 error information along with a search engine that allows you to quickly move to other content.

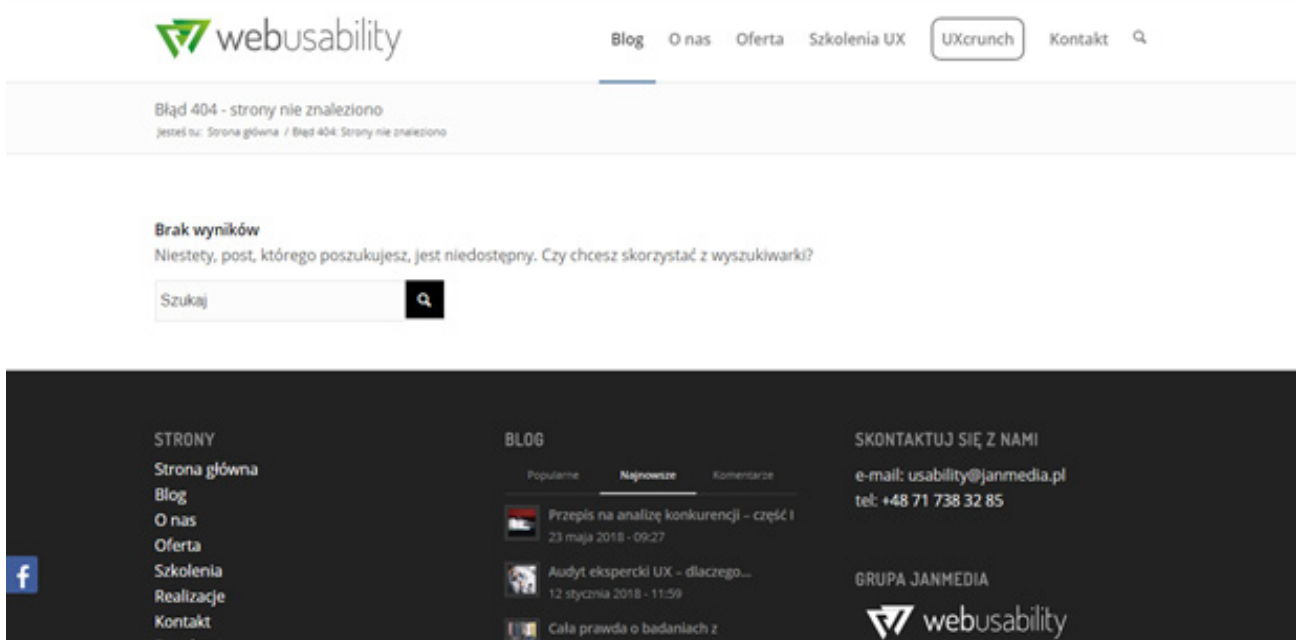

Source: ttps://www.webusability.pl/Tomasz_Karwatka-efektywa_efektowa_strona_www_sklep_internetowy.pdf (Access: 25.07.2018)

This solution was detected in a smaller part of the surveyed portals, because only in 21 out of 50 blogs there is a search engine on the error page 404 (see chart 11).

Chart 11. Ninth heuristics in the group of 50 blogs.

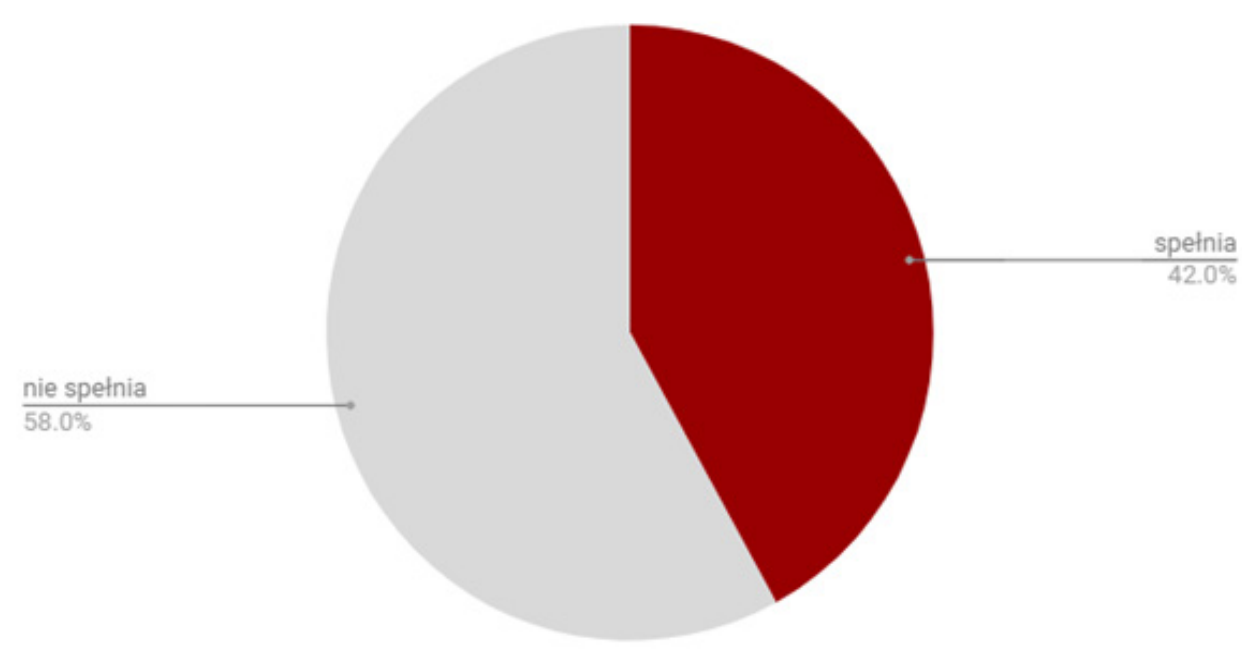

Source: Own elaboration

\section{Help and documentation}

The use of a help system for users in the case of complex websites is necessary to avoid wandering around their content. The website link itself should be visible and accessible from every service point. The instructions, in turn, must be legible and written in an accessible language in order to efficiently clarify issues related to a specific element of the website.

Designing a high-quality website can make it "self-explanatory" [Swackhamer, 2003] - this concept was proposed by Jason Swackhamer and means providing the possibility of using the website without the need to frequently look into the "Help" section. Navigating the site takes place then intuitively, all movements and actions of the recipient result from what he sees and how he understands what he sees. Thanks to this, 
access to most functions and content on the website becomes easier.

In the area of the blogosphere, we do not often deal with complex functions included in the interface that require explanation. However, due to the amount and degree of categorization of content, the creator of the blog can meet his readers by simply providing them with answers to frequently asked questions (the so-called FAQ [UXPin, 2017]) or providing tips on navigating the content of the site. The blog presented on an example (see Figure 15) has a prominent tab placed in the main menu called "Start here". The kind of introduction created in this way will speed up the knowledge of the website and the efficiency of moving around to new users.

Fig. 15. The "Start here" tab takes the new user to a kind of instruction and information about the content on the blog and how to navigate around it.

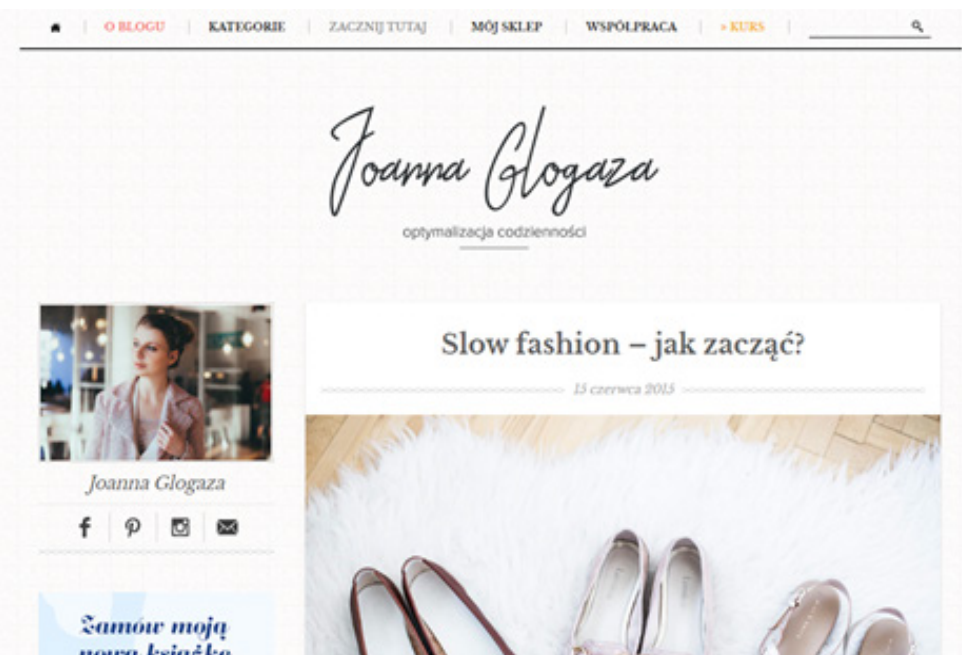

Source: https://joannaglogaza.com/2015/06/slow-fashion-jak-zaczac.html (Access: 25.07.2018)

After the qualitative study, it can be concluded that only $12 \%$ of blogs belonging to the analyzed group apply the same practice (see chart 12).

Chart 12. Tenth heuristics in the group of 50 blogs.

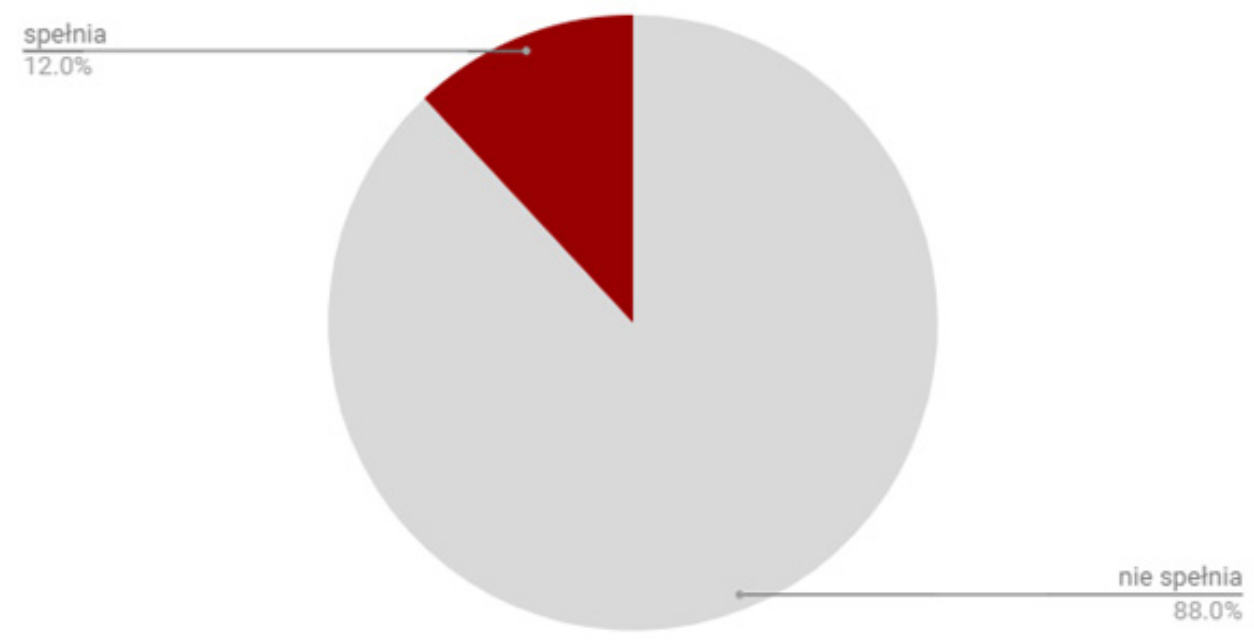

Source: Own elaboration 


\section{SUMMARY}

The conclusion obtained as a result of the above study shed light on the degree of utilization of $\mathrm{J}$. Nielsen's heuristics in the designs of interface elements of blogs in Poland. Many treatments refer to the list created by J. Nielsen, but the results testify to using them under the influence of the need to develop a part of the website's usability, probably not because the heuristics were accepted as an important tool for extending the usability and defined as right attempts to respond to all recommendations that affect the interaction of the recipient with published content.

In the group of blogs surveyed, only 2 of 50 meet 9 out of 10 heuristics. The occurrence of a blog meeting all the rules of utility is not found in the examined group. There was also no blog that did not meet any of the heuristics. The smallest number of confirmed heuristics within one blog were 1, which was found in 1 out of 50 blogs in the group (see Table 1).

Table 1. The distribution of the number of blogs in relation to the number of completed heuristics

\begin{tabular}{|c|c|}
\hline The number of completed heuristics & Number of blogs (max.50) \\
\hline 10 & 0 \\
\hline 9 & 2 \\
\hline 8 & 9 \\
\hline 7 & 11 \\
\hline 6 & 14 \\
\hline 5 & 7 \\
\hline 4 & 3 \\
\hline 3 & 2 \\
\hline 2 & 1 \\
\hline 1 & 1 \\
\hline 0 & 0 \\
\hline
\end{tabular}

Source: Own elaboration

The study conducted for the purpose of this article confirms the main hypothesis and indicates the level of occurrence of heuristics in the group of selected blogs at the level of 59.5\%. The number of fulfilled heuristics on individual blogs varies from 1 to 9 . The obtained percentage means the ratio of fulfilled to unfulfilled heuristics (see Chart 14). Interpreting this result, it can be stated that the Polish blogosphere strives for proper development in terms of technology and the aesthetics of the interface. 
Chart 14. Percentage distribution of fulfilled and unfulfilled heuristics in the studied group

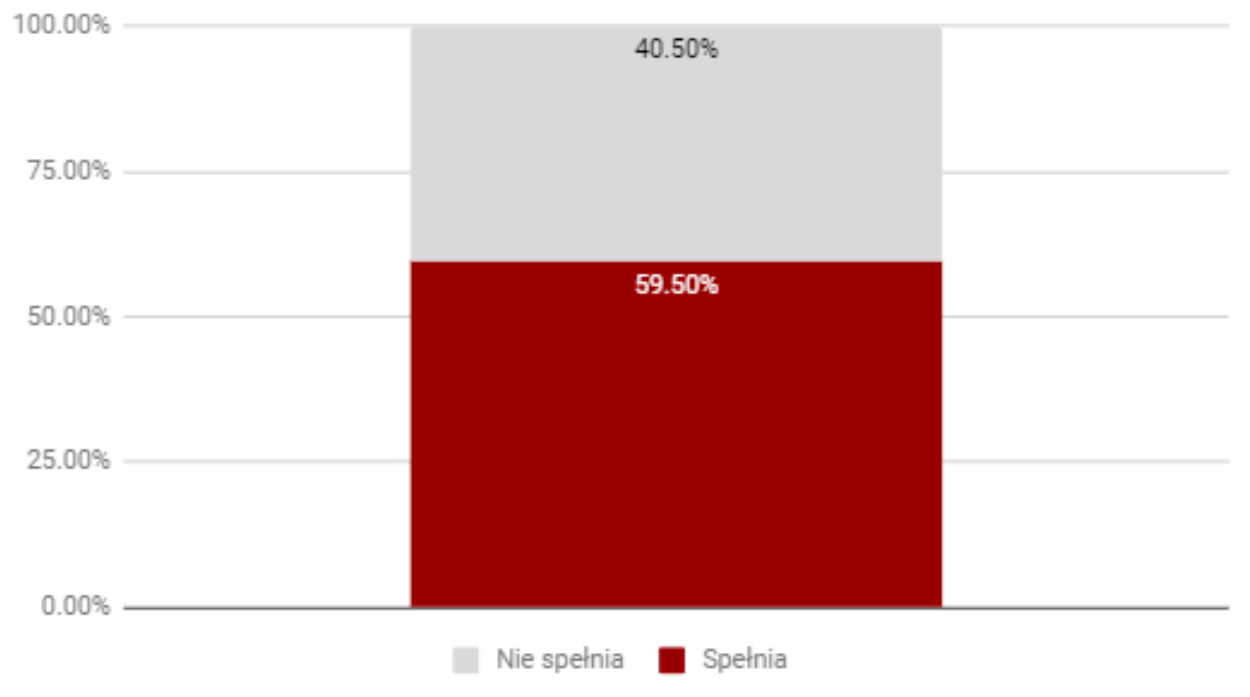

Source: Own elaboration

The study also shows that the most popular, and perhaps the easiest to apply, heuristics is 7 . Provide flexibility and efficiency ( $96 \%), 2$. Keep compatibility between the system and the reality (90\%) and 5. Prevent errors (88\%). The first one is about navigating the blog. The blog, due to the multitude of topics and connections between one content and the other, enforces facilitating the transition between subpages. Not much less important for bloggers is to create a place that is visually consistent with the topic of the blog and with it, remembering that it is a medium that reads not only on stationary devices, but also those portable, with a different resolution. It is interesting that despite the behavior of the 7th heuristic, concerning moving forward through the blog, you forget about the possibility of returning to previous content, which is discussed in principle 1. Show the status of the system ( $24 \%$ uses this heuristic). On the other hand, taking care of consistency of what the recipient sees (heuristics 2) and how he recognizes the codes on the site, only half of the respondents took care of aesthetics and moderation in the design of the blog (heuristics 8 . is used by $46 \%$ of blogs) (see chart 13 ).

Chart 13. Number of blogs that meet the given heuristic.

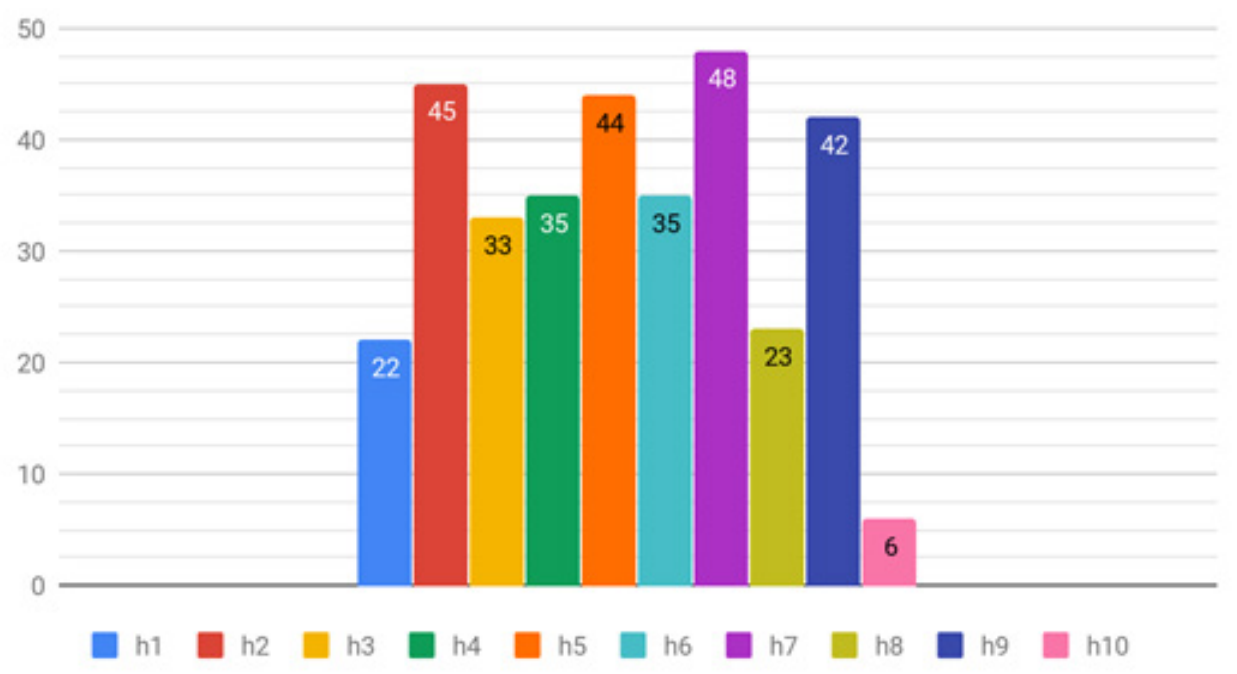

Source: Own elaboration 
The study raises a number of questions that go beyond the area of interest in heuristics. For example: Why do not blog authors use the FAQ (10th heuristics - 12\%)? Does this result from the nature of the medium? If so, it forces us to be interested in this nature. The role of the recipient located on the blog and giving him a part of control over the system (e.g. any interfering with comments left by him on the blog) is also interesting.

The qualitative study confirms the auxiliary hypotheses, where one can see a noticeable phenomenon that is the use of at least one or more practices referring to the heuristics defined by Nielsen. The lack of one or more of the ten heuristics does not define the design of the blog in advance as being of poor utility, but also does not cause that we can fully appreciate such a portal in terms of facilities offered to the recipients. The communicativeness of blogs certainly gains when he respects a great part of heuristics, thus offering the comfort of acquiring information to the user and performing various activities.

According to the authors, further directions of development of the use of heuristics in the Polish blogosphere focused on designing individual elements of interfaces using the principles formulated by J. Nielsen will have a positive impact on blogs growth, with particular emphasis on their role in the communication process. According to the results of the research, it can be assumed that using as many heuristics as possible within one blog can contribute to a visible increase in the communicativeness of the information transmission.

\section{References:}

GREGOR B., KACZOROWSKA-SPYCHALSKA D., Blogi w procesie komunikacji marketingowej, Wydawnictwo Uniwersytetu Łódzkiego, Łódź 2016

GUMKOWSKA A., MARYL M., TOCZYSKI P.,Blog to... blog. Blogi oczyma blogerów., Agora S.A., Warszawa 2009

HATALSKA N., Rola blogerów i youtuberów we współczesnym świecie / Raport, Urząd Miejski w Gdańsku, Gdańsk, Wrzesień 2016

KAZIMIROWICZ P., Krótki traktat o web usability, czyli gdzie mam kliknąć

KRUG S., Nie każ mi myśleć

LASKOWSKI M., Czynniki zwiększające jakość użytkową interfejsów aplikacji internetowych [w:] LOGISTYKA, Lublin 2011

NIELSEN J., BUDIU R., Funkcjonalność aplikacji mobilnych, Helion, Gliwice 2013

SCOTT D.M., Nowe zasady marketingu PR, Oficyna Wolers Kluwer Business, Warszawa 2009

UXPIN. 10 pro tips to a smarter UX design process

UXPIN, Designing Better UX With UI Patterns

UXPIN, Web UI trends, Presence and Future. The Elegance of Minimalism

Internet:

https://bezprawnik.pl/toga-prawnicza/ (Access: 19.07.2018)

http://www.kroplamorza.pl/jaki-wybrac-system-komentarzy-na-bloga/ (Access: 20.07.2018)

https://www.nngroup.com/articles/ten-usability-heuristics/ (Access: 14.07.2018)

https://searchmicroservices.techtarget.com/definition/user-interface-UI (Access: 02.08.2018)

Swackhamer J., Don't make me think!, prezentacja na Great Lake Web Professionals (Access: 08.05.2003)

https://takaoto.pro/heurystyki-ux-przy-tworzeniu-tekstow/ (Access: 14.07.2018).

http://usability.edu.pl/wprowadzenie/definicje-najwazniejszych-pojec/ (Access: 02.08.2018) 